удК 316.6

Н. С. Фонталова

Байкальский государственный университет, г. Иркутск, Российккая Федерация

\title{
ОТНОШЕНИЕ К ИЗМЕНЕ У СОВРЕМЕННОЙ МОЛОДЕЖИ
}

\begin{abstract}
АНнотАция. Статья посвящена изучению отношения современной молодежи к измене. Актуальность данной работы не вызывает сомнения, так как данную проблему необходимо целенаправленно изучать в целях эффективной воспитательной работы среди молодежи, направленной на формирование адекватного представления о семье и браке. Анализ современной научной литературы показывает слабую разработанность рассматриваемой темы, поэтому для выявления отношения молодежи к измене было проведено эмпирическое исследование. Выборку составили 120 чел. (из них 60 чел. - молодежь и 60 чел. - зрелого возраста). Особый интерес вызывает практическая значимость исследования, состоящая в том, что полученные выводы могут быть использованы не только психологами-практиками, но и специалистами в различных отраслях социологии, педагогики и юриспруденции.

кЛючЕВЫЕ СЛОВА. Молодежь; измена; семья; отношения; неверность; психологическое здоровье; интересы; увлечения.

ИНФОРМАЦИЯ О СТАТЬЕ. Дата поступления 23 марта 2016 г.; дата принятия к печати 20 апреля 2016 г.; дата онлайн-размещения 29 июля 2016 г.
\end{abstract}

N. S. Fontalova

Baikal State University,

Irkutsk, Russian Federation

\section{MODERN YOUNG PEOPLE'S ATTITUDE TO ADULTERY}

\begin{abstract}
The article is devoted to investigating modern young people' attitude to adultery. The topicality of this paper is beyond any doubt as this problem must be purposely studied with the view of awareness-raising work with young people aimed at building adequate image of the family and marriage. An analysis of modern research literature reveals poor scientific development of this issue, that's why, an empiric investigation is made in order to identify young people's attitude to adultery. The sample covers 120 people (among them 60 young people and 60 adults). Of special interest is practical significance of the investigation consisting of the fact that the conclusion made can be used not only by expert psychologists but by specialists in various fields of psychology, pedagogics and jurisprudence.
\end{abstract}

KEYWORDS. Young people; adultery; family; attitudes; infidelity; psychological health; interests; hobbies.

ARTICLE INFO. Received March 23, 2016; accepted April 20, 2016; available online July 29, 2016.

Близкие доверительные партнерские отношения являются важным фактором психологического здоровья личности. Стабильные диадические отношения занимают одно из первых мест в иерархии общечеловеческих ценностей. Значимость близких отношений определяется их влиянием на эмоциональное благополучие и психологический комфорт личности, удовлетворением базовой потребности в любви [1-3].

Неверность является второй по распространенности причиной разводов. Измена, возникающая в отношениях, является травмирующей ситуацией для большинства людей. Она характеризуется неоднозначностью переживаний, отрицательными эмоциями, высокой потенциальной разрушительностью. Измена, как правило, влечет за собой угрозу потери значимого человека, разрыв важных отношений, из-

(C) Н.С.Фонталова, 2016

\section{Baikal Research Journal}

электронный научный журнал Байкальского государственного университета 
менение общего уклада жизни. Она считается одним из тяжелейших ненормативных кризисов жизни человека [4-9].

Проблемой подготовки молодежи к будущей семейной жизни занимались такие ученые, как Т. А. Долбик-Воробей, Е. А. Данилова, М. Зимина, Н. Устинова, В. Т. Лисовский и др. [10-13]. Вопросы развития системы ценностей в социальной среде также затрагивались рядом известных авторов, в том числе Г. Оллпортом, Дж. Гиллепси, М. Рокичем, многими отечественными психологами [1; 3; 5; 7]. Актуальность исследования обусловлена наличием противоречия между важностью изучения этой тематики и недостатком теоретических и эмпирических данных о ней.

Цель нашей работы состояла в изучении особенностей отношения к измене у современной молодежи.

Мы предположили, что отношение к супружеским изменам у современной молодежи имеет определенные особенности, которые могут проявляться в зависимости от возраста и пола респондента, а также от отношения к противоположному полу и к семье.

В исследовании приняли участие 120 чел. (из них 60 чел. - зрелого возраста, 60 чел. - молодежь). В группе людей зрелого возраста 55 чел. состоят в зарегистрированном браке, 5 из них не имеют партнера, или имеют незарегистрированные отношения. В группе молодежи только половина состоят в зарегистрированном браке, остальные предпочитают гражданский брак.

Исследование проводилось на базе Байкальского государственного университета и Иркутского авиационного завода.

В исследовании нами были использованы следующие методики:

- авторская анкета - направленная и разработанная с целью выяснения отношения к собственной родительской семье, к семье в целом и будущей семейной жизни;

- ассоциативное исследование - респондентам предлагалось написать 20 ассоциаций со словом «измена»;

- методика «Незаконченные предложения» - позволяет исследовать отношение к своей семье и противоположному полу;

- методика «Понимание верности» - дает возможность сформулировать понимание у молодых людей содержания понятия верности, а также наличия данного качества у себя [14].

Авторская анкета позволила выявить представления молодых людей о источниках крепких взаимоотношений в парах, а также о том, сколько нужно времени, чтобы подготовиться к браку.

На вопрос «Сколько нужно встречаться до момента официальной регистрации отношений?» большая часть респондентов считают, что прежде, чем выходить замуж (жениться), необходимо сохранять отношения как минимум год. Такой промежуток до официальной регистрации молодые люди объясняют тем, что им необходимо время, чтобы узнать своего партнера и понять сможет ли он (она) прожить с данным человеком остаток своей жизни. Отсюда следует, что в настоящее время получил распространение такой феномен, как «гражданский брак». Такой брак - это как бы репетиция партнеров прожить жизнь как супруги: молодые люди начинают жить вместе, их быт объединяется, а в некоторых случаях даже их бюджет становится общим и т. д.

Однако 37 \% опрошенных полагают, что выходить замуж (жениться) можно уже через полгода после знакомства. Причем к такому мнению склоняются люди более зрелого возраста, так как у них осталось мало времени для того, чтобы выйти замуж (жениться), родить ребенка и не остаться «в девках» (по большей степени перечисленные характеристики свойственны женскому полу).

И всего $2 \%$ опрошенных молодых людей уверены, что прежде, чем зарегистрировать официально свои отношения, необходимо повстречаться два года. Такое мне-

\section{Baikal Research Journal}


ние в основном свойственно молодым людям в возрасте $25-27$ лет, поэтому очень мало респондентов выбрали данный вариант ответа.

Относительно того, что лежит в основе взаимоотношений между мужчиной и женщиной, большая часть опрошенных (35 \%) уверены, что это доверие. В данном случае именно благодаря доверию можно выстраивать доверительные отношения, которые выступают залогом крепких семейных уз. Ведь если нет доверия, в таком случае муж (жена) будут постоянно подозревать в чем-либо своего избранника.

На второе место молодые люди поставили взаимные симпатии как основу взаимоотношений мужчин и женщин. Данный параметр выбрали 30 \% респондентов. Симпатии - основа любви. Именно любовь помогает сохранить брак, так как это чувство позволяет мужчинам (женщинам) не видеть недостатки своего партнера.

На третьем по значимости месте были определены общие интересы и увлечения как основа взаимоотношений между мужчиной и женщиной. Данный показатель выбрали 20 \% опрошенных. Именно общие интересы и увлечения позволяют супругам больше времени проводить вместе, планировать совместный досуг, не раздражая при этом друг друга, a, напротив, получать с удовольствие от совместного общения.

На последнем месте в качестве показателя крепких взаимоотношений между мужчиной и женщиной находится искренность, которая выступает в качестве основы доверительных отношений между супругами (15\%).

По итогам исследования в целом было выявлено, что 65 \% опрошенных состоят в зарегистрированном браке (рис. 1). При этом из числа тех, кто состоит в браке, $30 \%$ меньше года назад узаконили свои отношения, 45 \% уже больше года состоят в законных отношениях со своим партнером и оставшиеся $25 \%$ опрошенных уже более двух лет проживают в браке.

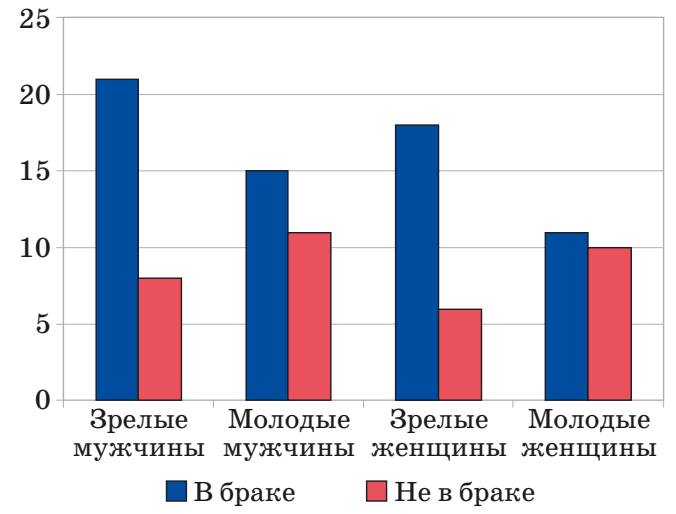

Рис. 1. Количество опрошенных, состоящих в зарегистрированном браке, \%

Оценивая содержательную характеристику своих отношений, 50 \% опрошенных отметили, что у них нормальные взаимоотношения со своим партнером, 30 \% считают свои отношения с партнером не очень хорошими, а $20 \%$ респондентов дали оценку «отлично» своим отношениям. Таким образом, полученные данные свидетельствуют о том, что в целом среди опрошенных молодых людей преобладают достаточно крепкие отношения. На основании этого можно предположить, что эти молодые люди негативно относятся к измене и не станут изменять своему партнеру.

Ответы на вопрос «Почему женщины не хотят рано вступать в брак?» распределились следующим образом: по большей части не стремятся рано выходить замуж, так как у них не будет возможности для решения собственных планов, профессиональной самореализации. Это обусловлено тем, что при вступлении в законные отношения женщина приобретает новую социальную роль жены, предполагающую

\section{Baikal Research Journal}


выполнение определенного набора функциональных обязанностей (готовка, уборка, рождение детей и т. д.). Все это становится барьером к самореализации женщины, и она встает перед выбором - семья или работа.

Среди опрошенных молодых людей только 30 \% имеют детей. При этом в парах, где есть дети, им уделяется довольно много времени. На это указало 75 \% опрошенных.

Полученные данные свидетельствуют о следующем:

- современные молодые люди не спешат рано заводить детей, чтобы больше времени уделить друг другу;

- отсутствие детей можно считать негативным фактором, который может стать причиной формирования у партнера желания изменить.

На рис. 2 представлены предпочтения студентов в выборе форм брачно-семейных отношений.

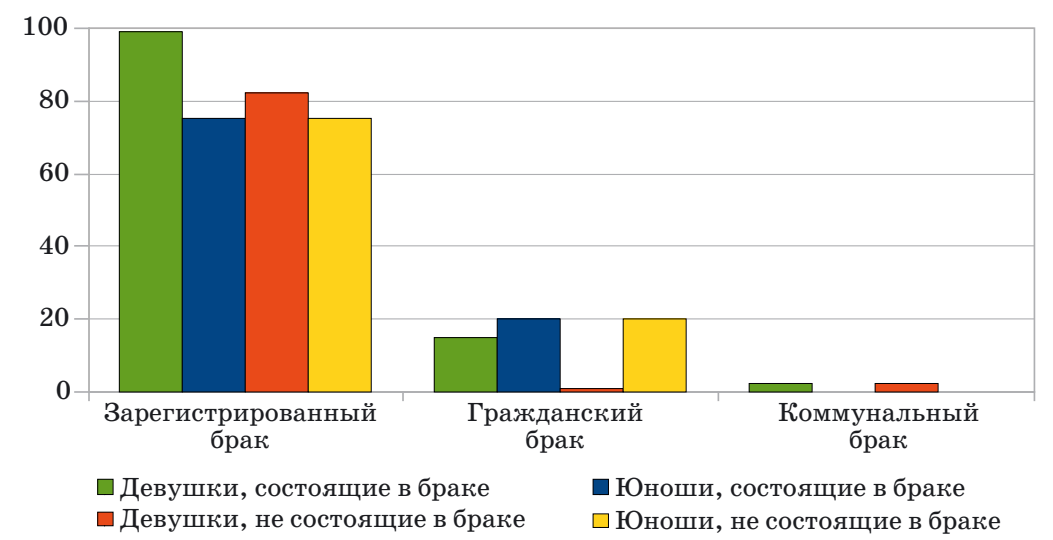

Рис. 2. Предпочтение форм брачно-семейных отношений студентали, \%

Судя по полученным сведениям, респонденты к моменту наступления зрелости уже основывают семьи, живущие дольше двух лет. В среде молодежи доля отношений, превысивших срок в 2 года, уже значительно меньше. Кроме того, выяснилось, что молодые мужчины в значимо меньшей степени настроены на длительные отношения.

Результаты ассоциативного эксперимента показали следующие результаты: ассоциации мужчин и женщин разных возрастных категорий различны.

В первую очередь мы проанализируем результаты мужчин и женщин зрелого возраста. Так, данные свидетельствуют о том, что наибольшее количество выборов в женской зрелой группе набрали такие ассоциации к слову «измена», как:

- предательство - $80 \%$;

- ревность - $60 \%$;

- боль $-90 \%$;

- разочарование - $45 \%$;

- обида $-70 \%$;

- страх - $50 \%$;

- обман $-50 \%$;

- общение - $45 \%$;

- ненависть - $55 \%$;

- тревога - $60 \%$.

Судя по перечисленным характеристикам, опрошенным женщинам зрелого возраста приходилось пережить измену своего партнера, поэтому были отобраны такие ассоциации, как предательство, ревность, боль, обман. Кроме того, 45 \% опрошенных выбрали такую ассоциацию, как разочарование. Можно предположить, что эти

\section{Baikal Research Journal}


женщины находились под влиянием соблазна измены, но были разочарованы как в целом в таких отношениях, так и в любовнике.

В свою очередь, анализируя ассоциации мужчин зрелого возраста, можно сформулировать следующие выводы. Наибольшее количество предпочтений получили следующие ассоциации:

- секс - $80 \%$;

- новизна - $65 \%$.

Таким образом, можно предположить, что для мужчин зрелого возраста измена - это просто интрижка, в эти отношения они не вкладывают ничего серьезного: простое физическое влечение и желание ощутить новые эмоции.

Проанализируем сравнительную характеристику ассоциативного ряда измены у мужчин и женщин зрелого возраста (табл. 1). Отметим, что для женщин зрелого возраста измена ассоциируется с бо́льшими эмоциональными потерями, чем для мужчин зрелого возраста. Для вторых измена - это форма развлечения, серьезности чувств в данном случае не предполагается.

Таблица 1

Сводные данные результатов ассоциативного эксперилента мужчин и женшин зрелого возраста, \%

\begin{tabular}{|l|r|r|}
\hline \multicolumn{1}{|c|}{ Ассоциация } & Выбор женщин & Выбор мужчин \\
\hline Месть & 5 & 25 \\
\hline Предательство & 80 & 10 \\
\hline Ревность & 60 & 10 \\
\hline Боль & 90 & 10 \\
\hline Разлука & 20 & 10 \\
\hline Секс & 30 & 80 \\
\hline Разочарование & 45 & 40 \\
\hline Новизна & 10 & 65 \\
\hline Обида & 70 & 10 \\
\hline Скука & 10 & 30 \\
\hline Любовь & 30 & 10 \\
\hline Отношения & 40 & 10 \\
\hline Спокойствие & 15 & 10 \\
\hline Страх & 50 & 10 \\
\hline Жизнь & 10 & 10 \\
\hline Обман & 70 & 30 \\
\hline Развлечение & 20 & 40 \\
\hline Общение & 45 & 10 \\
\hline Ненависть & 55 & 10 \\
\hline Тревога & 60 & 10 \\
\hline
\end{tabular}

В женской молодежной группе данные ассоциативного эксперимента свидетельствуют о том, что чаще всего встречаются такие ассоциации к слову «измена», как:

- обман - $90 \%$;

- предательство - $85 \%$;

- обида - $80 \%$;

- ненависть - $75 \%$;

- ревность - $70 \%$;

- страх - $70 \%$;

Можно предположить, что женщины молодого возраста, вступая в отношения или узаконивая их, живут со страхом о том, что их партнер способен на измену, у них выражена ревность, и они опасаются обмана и предательства со стороны близкого человека.

\section{Baikal Research Journal}


Проанализировав ассоциации мужчин молодого возраста, обнаружили, что в молодежной мужской группе наибольшее количество набрали такие ассоциации $\mathrm{\kappa}$ слову «измена», как:

- секс - $95 \%$;

- скука $-90 \%$;

- развлечение - $90 \%$;

- новизна - $85 \%$;

- общение $-70 \%$.

Таким образом, можно предположить, что для мужчин молодого возраста измена - это не более чем просто удовлетворение физической потребности, она может возникнуть, если отношения наскучили, по большей степени они не придают измене никого значения. Для них это развлечение, новое общение.

Для женщин молодого возраста измена ассоциируется с большими эмоциональными потерями, чем для мужчин такого же возраста (табл. 2), также как и для женщин зрелого возраста. Женщины молодого возраста намного серьезнее относятся к измене, чем мужчины молодого возраста, им важно сохранить в браке доверительные отношения, они боятся предательства, обмана со стороны партнера. Мужчины молодого возраста относятся к измене, как к развлечению.

Таблица 2

\section{Сводные данные результатов ассоциативного эксперимента} мужчин и женщин молодого возраста, \%

\begin{tabular}{|l|r|r|}
\hline \multicolumn{1}{|c|}{ Ассоциация } & Выбор женщин & Выбор мужчин \\
\hline Месть & 20 & 30 \\
\hline Предательство & 85 & 40 \\
\hline Ревность & 70 & 50 \\
\hline Боль & 60 & 40 \\
\hline Разлука & 40 & 55 \\
\hline Секс & 25 & 95 \\
\hline Разочарование & 70 & 50 \\
\hline Новизна & 5 & 85 \\
\hline Обида & 80 & 40 \\
\hline Скука & 5 & 90 \\
\hline Любовь & 10 & 10 \\
\hline Отношения & 15 & 15 \\
\hline Спокойствие & 10 & 10 \\
\hline Страх & 70 & 30 \\
\hline Жизнь & 10 & 10 \\
\hline Обман & 90 & 50 \\
\hline Развлечение & 20 & 90 \\
\hline Общение & 30 & 70 \\
\hline Ненависть & 75 & 55 \\
\hline Тревога & 50 & 40 \\
\hline
\end{tabular}

Анализируя сводные данные по ассоциативной методике мужчин и женщин молодого и зрелого возраста (табл. 3), можно сделать вывод о том, что для женщин как молодого, так и зрелого возраста измена ассоциируется с большими эмоциональными потерями, для них важно сохранить доверие в отношениях, они боятся обмана и предательства. Было также выявлено, что женщины в зрелом возрасте болезненнее относятся к измене, это может быть связанно с тем, что у них семьи с достаточно большим стажем, есть дети и им эмоционально тяжелее пережить измену. Мужчины молодого возраста склонны к большей ревности к своему партнеру, к измене они относятся как

\section{Baikal Research Journal}


к развлечению, для них это способ завести новые знакомства. Для мужчин зрелого возраста измена это секс, поиск новых ощущений, это может быть связанно с тем, что мужчине в зрелом возрасте важно чувствовать себя востребованным.

Сводные данные результатов ассоциативного эксперимента Таблица 3 мужчин и женщин молодого и зрелого возраста, \%

\begin{tabular}{|l|r|r|r|r|}
\hline \multirow{2}{*}{ Ассоциация } & \multicolumn{2}{|c|}{ Молодой возраст } & \multicolumn{2}{c|}{ Зрелый возраст } \\
\cline { 2 - 6 } & женщины & мужчины & женщины & мужчины \\
\hline Месть & 20 & 30 & 5 & 25 \\
\hline Предательство & 85 & 40 & 80 & 10 \\
\hline Ревность & 70 & 50 & 60 & 10 \\
\hline Боль & 60 & 40 & 90 & 10 \\
\hline Разлука & 40 & 55 & 20 & 10 \\
\hline Секс & 25 & 95 & 30 & 80 \\
\hline Разочарование & 70 & 50 & 45 & 40 \\
\hline Новизна & 5 & 85 & 10 & 65 \\
\hline Обида & 80 & 40 & 70 & 10 \\
\hline Скука & 5 & 90 & 10 & 30 \\
\hline Любовь & 10 & 10 & 30 & 10 \\
\hline Отношения & 15 & 15 & 40 & 10 \\
\hline Спокойствие & 10 & 10 & 15 & 10 \\
\hline Страх & 70 & 30 & 50 & 10 \\
\hline Жизнь & 10 & 10 & 10 & 10 \\
\hline Обман & 90 & 50 & 70 & 30 \\
\hline Развлечение & 20 & 90 & 20 & 40 \\
\hline Общение & 30 & 70 & 45 & 10 \\
\hline Ненависть & 75 & 55 & 55 & 10 \\
\hline Тревога & 50 & 40 & 60 & 10 \\
\hline
\end{tabular}

Традиционно в обществе считается, что люди чаще всего идут на измену во время кризиса середины жизни. В этот период люди, подводя итоги своей жизни, начинают ощущать, что они еще не сделали очень многое из запланированного когда-то, отрицают возрастные изменения, происходящие с их телом, памятью, мышлением. Как результат, они делают несвойственные им раньше вещи для поддержания ощущения внутренней молодости, в том числе заводят связи на стороне.

Анализируя результаты ответов респондентов по методике «Незаконченные предложения», можно сказать, что субъективное отношение к семье и противоположному полу практически не зависит от того, состоит человек в зарегистрированном браке или нет, небольшие изменения наблюдались лишь среди респондентов зрелого возраста, находящиеся в официальных отношениях со своими партнерами. Наиболее существенная разница во взглядах продемонстрирована представителями разных полов в независимости от возраста, т. е. ярко выражены гендерные особенности отношения к семье и противоположному полу.

Однако когнитивный компонент отношения к семье и противоположному полу у мужчин и женщин, т. е. их мнение об объекте, имеет существенные различия. Так, 32,1 \% всех опрошенных зрелых женщин считают, что по сравнению с большинством других семей, их семья отличается сплоченностью, принятием всех членов семьи, отзывчивостью. В то же время 12,0 \% респондентов мужского (зрелых) пола сошлись во мнении, что их семья отличается наличием детей, стремлением всей семьи к достижению одних целей. Интересными, на наш взгляд, были формулировки при ответе на вопрос «Идеалом женщины (или мужчины) для меня явля-

\section{Baikal Research Journal}

электронный научный журнал Байкальского государственного университета 
ется». Практически все респонденты как зрелого, так и молодого возраста ответили «мать» и «отец». Так считают $95 \%$ всех мужчин и $97 \%$ всех женщин.

По последней методике, направленной на определение своего понимания верности, $61 \%$ набрали по 10-15 балов, что свидетельствует о том, что большинство испытуемых в своем возрасте придают огромное значение верности, нежности, постоянству, и того же требуют от партнера.

Таким образом, в результате проведенного исследования можно сформулировать следующие основные выводы:

1. Общее отношение к измене отрицательное в любом возрасте. При этом для молодых людей измена - это самая настоящая трагедия в жизни, для взрослых - это предательство всей семьи вместе с детьми, для зрелых - это показатель, что что-то надо менять в отношениях. Результаты исследования говорят о том, что наиболее склонны к изменам представители взрослого возраста, но со значительной оговоркой: они склоны к изменам в случае ощущения внутреннего разочарования, что жизнь идет совершенно не так, как планировалось в молодости.

2. Среди молодых людей выделяются как те, кто отрицательно относится к измене как факту, и те, кто не против изменить своему партнеру. При этом необходимо отметить, что по большей части эмоциональность измене придается женщинами, мужчины в данном случае гораздо хладнокровнее.

3. Отношение к изменам отличается значимо не только в зависимости от возраста, но и в зависимости от пола. Так, например, группа молодых респондентов мужского пола (не вступивших в брак) в большей степени не считает измену запретной формой поведения - их отношение к измене простое, а к отношениям - не обязывающее.

Тем не менее необходимо отметить, что в целом, у студентов Байкальского государственного университета положительное представление о семье и ценностях семьи.

\section{Список использованной литературы}

1. Агапов Е. П. Семьеведение : учеб. пособие / Е. В. Агапов, О.А. Нор-Аревян. - М. : Дашков и $\mathrm{K}^{\circ}$; Ростов н/Д : Наука-Спектр, 2010. - 400 с.

2. Андреева Т. В. Психология современной семьи : монография / Т. В. Андреева. - СПб. : Речь, 2009. - 436 с.

3. Седракян С. Социальная психология семьи / С. Седракян. - М. : Моск. психол.-соц. ин-т, 2011. - 368 с.

4. Белинская А. Б. Профилактика и разрешение семейных конфликтов на разных этапах развития семьи : учеб.-метод. пособие / А. Б. Белинская. - М. : Ин-т соц. педагогики Рос. акад. образования, $2012 .-79 \mathrm{c}$.

5. Калинина Р. Р. Введение в психологию семейных отношений / Р. Р. Калинина. СПб. : Речь, 2013. - 352 c.

6. Крюкова Т. Л. Психология семьи: жизненные трудности и совладание с ними / Т. Л. Крюкова, М. В. Сапоровская, Е. В. Куфтяк. - СПб. : Речь, 2007. - 86 с.

7. Фонталова Н. С. Психология семьи и семейное консультирование : учеб. пособие / Н. С. Фонталова. - Иркутск : Изд-во БГУЭП, 2013. - 136 с.

8. Фрейд Дж. Психология предательства и измены / Дж. Фрейд, П. Биррелл. - СПб. : Питер, 2013. - 192 с.

9. Цветкова Н. Семейная жизнь без кризисов / Н. Цветкова. - М. : Центрполиграф, 2010. $-160 \mathrm{c}$.

10. Данилова Е. А. Семья как важнейшая ценность молодежи Республики Беларусь / Е. А. Данилова // Весник Белорусского государственного университета. Сер. 3, История. Экономика. Право. - 2007. - № 3. - С. 66-69.

11. Долбик-Воробей Т. А. Студенческая молодежь о проблемах брака и рождаемости / Т. А. Долбик-Воробей // Социологические исследования. - 2003. - № 11. - С. 78-83.

12. Лисовский В. Т. Молодежь: любовь, брак, семья (Социологическое исследование) / В. Т. Лисовский. - СПб. : Наука, 2009. - 368 с.

\section{Baikal Research Journal}

электронный научный журнал Байкальского государственного университета 
13. Энциклопедия молодой семьи / сост. М. Зимина, Н. Устинова. — М. : Эксмо, 2008. $480 \mathrm{c}$.

14. Терехова Т. А. Психодиагностика : учеб. пособие / Т. А. Терехова. - Иркутск : БГУЭП, 2010. - 403 с.

\section{References}

1. Agapov E. P., Nor-Arevyan O. A. Sem'evedenie [Family studies]. Moscow, Dashkov i $\mathrm{K}^{\circ}$ Publ., Rostov-on-Don, Nauka-Spektr Publ., 2010. 400 p.

2. Andreyeva T. V. Psikhologiya sovremennoi sem'i [Psychology of modern family]. Saint Petersburg, Rech' Publ., 2009. 436 p.

3. Sedrakyan S. Sotsial'naya psikhologiya sem'i [Social psychology of family]. Moscow, Psychology-Social Institute Publ., 2011. 368 p.

4. Belinskaya A. B. Profilaktika i razreshenie semeinykh konfliktov na raznykh etapakh razvitiya sem' $i$ [Preventive measures and solution of family conflicts at various stages of family development]. Moscow, Institute of Social Pedagogics, Russian Academy of Education Publ., 2012. 79 p.

5. Kalinina R. R. Vvedenie $v$ psikhologiyu semeinykh otnoshenii [Introduction into psychology of family relations. Saint Petersburg, Rech' Publ., 2013. 352 p.

6. Kryukova T. L., Saporovskaya M. V., Kuftyak E. V. Psikhologiya sem'i: zhiznennye trud nosti i sovladanie s nimi [Family psychology: life difficulties and putting up with them]. Saint Petersburg, Rech' Publ., 2007. 86 p.

7. Fontalova N. S. Psikhologiya sem'i i semeinoe konsul'tirovanie [Family psychology and family counseling]. Irkutsk, Baikal State University of Economics and Law Publ., 2013. 136 p.

8. Freyd Jennifer J., Birrell P. Blind to Betrayal: Why We Fool Ourselves We Aren't Being Fooled. New York, Wiley, 2013. 224 p. (Russ. ed.: Freid J., Birrell P. Psikhologiya predatel'stva i izmeny. Saint Petersburg, Piter Publ., 2013. 192 p.).

9. Tsvetkova N. Semeinaya zhizn' bez krizisov [Family life without crises]. Moscow, Tsentrpoligraf Publ., 2010. 160 p.

10. Danilova E. A. Family as the most important value for youth of the Republic of Belorus. Vesnik Belorusskogo gosudarstvennogo universiteta. Seriya. 3, Istoriya. Ekonomika. Pravo = Bulletin of Belarusian State University, Series 3, History. Economy. Law, 2007, no. 3, pp. 66-69. (In Russian).

11. Dolbik-Vorobey T. A. S College students about problems of marriage and childbirth. Sotsiologicheskie issledovaniya = Sociological Studies, 2003, no. 11, pp. 78-83. (In Russian).

12. Lisovsky V. T. Molodezh': lyubov', brak, sem'ya (Sotsiologicheskoe issledovanie) [Young people: love, marriage, family (Sociological study) Saint Petersburg, Nauka Publ., 2009. 368 p.

13. Zimina M., Ustinova N. (eds). Entsiklopediya molodoi sem'i [Encyclopedia of Young Family]. Moscow, Eksmo Publ., 2008. 480 p.

14. Terekhova T. A. Psikhodiagnostika [Psychodiagnosis]. Irkutsk, Baikal State University Economics and Law Publ., 2010. 403 p.

\section{Информация об авторе}

Фонталова Наталья Сергеевна - кандидат психологических наук, доцент, кафедра социальной и экономической психологии, Байкальский государственный университет, 664003, г. Иркутск, ул. Ленина, 11, e-mail: fontalova.n@mail.ru.

\section{Author}

Natalya S. Fontalova - PhD in Psychology, Associate Professor, Chair of Social and Economic Psychology, Baikal State University, 11 Lenin St., 664003, Irkutsk, Russian Federation; e-mail: fontalova.n@mail.ru.

\section{Библиографическое описание статьи}

Фонталова Н. С. Отношение к измене у современной молодежи / Н. С. Фонталова / Baikal Research Journal. — 2016. — T. 7, № 4. - DOI : 10.17150/2411-6262.2016.7(4).25.

\section{Reference to article}

Fontalova N. S. Modern young people's attitude to adultery. Baikal Research Journal, 2016, vol. 7, no. 4. DOI : 10.17150/2411-6262.2016.7(4).25. (In Russian).

\section{Baikal Research Journal}

